\title{
Effects Of Cognitive Restructuring And Problem Solving Strategies On Reading And Note Taking Of Secondary School Students In Ondo State, Nigeria
}

\author{
Olowolabi Segun (Ph.D.) \\ Department of Guidance and Counselling \\ Faculty of Education, Adekunle Ajasin University \\ Akungba-Akoko, Ondo State, Nigeria
}

\begin{abstract}
The recurring problem of low academic achievement among secondary school students has been attributed to many factors among which are poor reading skills and note taking behavior which are the concern of this study. The study investigated the effects of cognitive restructuring and problem-solving strategies in the treatment of poor reading skills and note taking among secondary school students in Ondo State. The study adopted quasi experimental pre-test, post-test and control group research design. One hundred and twenty subjects (120) were selected through purposive and stratified random sampling techniques from three secondary schools in Ondo state. One school from each of three senatorial districts of Ondo State. Samples were assigned to three groups: cognitive restructuring, problem-solving and control groups. Each group consisted of forty subjects. Instrument used for the study was Study Habit Inventory (SHI) adapted from Bakare's Study Habit Inventory (1977). Two hypotheses were tested at 0.05 alpha level. Data collected were analyzed using analysis of covariance (ANCOVA). Results of the study revealed that there was significant difference in the reading and note taking of experimental group and control group. The treatment strategies: Cognitive Restructuring and Problem-Solving techniques assisted in improving reading and note taking of the respondents. Based on the findings, it was concluded that application of Cognitive Restructuring and Problem-solving Strategies are capable of ameliorating poor reading skills and note taking of secondary school students. Therefore, it was recommended that Teachers, Counsellors, Psychologists, and other stakeholders in education need to embark upon administering cognitive restructuring and problem-solving strategies by training of stakeholders on the two strategies so as to improve reading skills and note-taking to enhance reading culture and good academic performance among students.
\end{abstract}

Keywords: cognitive restructuring, problem solving strategy, note-taking, reading skills.

\section{INTRODUCTION}

The problem of low academic achievement and increasing rate of examination malpractices over the years has indeed become a matter of concern to many stakeholders in education. A lot of reasons might be responsible for this ugly trend which could include poor study habits, inability to properly plan and organize time for study, poor note taking and ineffective methods of preparing and taking examinations. Others may be low motivation, lack of information and interest, dislike for certain teachers and learning environment, and poor reading habits.

This seeming poor performance and mass failure in examinations, according to Hussain (2006), is attributed to students' poor study habits. Azeez (2009) in his study found that poor study habits ranked highest when compared with other factors responsible for poor academic performance among students. Similarly, a pilot-study conducted by Anwar (2013) to 
investigate the degree of relationship between study habits and academic achievement of senior secondary school students of Lucknow city of U.P. (India) found that the academic achievement of the students having good and poor study habits differed significantly in favour of those who has good study habits. It also revealed that significant number of students expressed concern on how to plan and organize time for study, note taking techniques, learning and remembering strategies, use of library, preparing and taking examination and how to curb excessive examination anxiety.

As stated by Pitan (2011), the values of reading cannot be overemphasized as he further affirmed. Through reading, according to him, human beings have the tools to transmit knowledge to each succeeding generation. Pitan further asserted that every child must be fully competent in reading to succeed in school and discharge responsibilities as a citizen in a democratic society. Reading is the foundation of much enjoyment in life and could be related to vocational efficiency. These submissions however signaled that lack of reading skill can be the cause of this educational problem, termed poor study habits.

Children with poor reading habit receive poor grades in school, get easily distracted and frustrated. According to Pitan (2011), children with poor reading habits have a higher chance of engaging in anti-social behaviours, like delinquency, truancy, school violence, bullying, hacking computers and examination malpractices. While poor reading habit can be instrumental to the destruction of any individual who is plagued with it, good reading habit do help to develop steadily and build a constructive mind. According to him, good reading skill matures into good study habits.

Note taking is an art in itself and valuable aid to remembering. Notes are important summary of main parts and important details of a text. A challenge to counselling here is that students should be assisted to acquire or develop mote taking skill. To do that, students should be made to read passages and as far as possible jotting down important ideas in their own words. They should be told that notes can be made after a text has been understood and that should be brief and accurate.

Lee, Wang, Hamman and Huang (2013) and Haghverdi, Biria and Karimi (2010) argued on the other hand that there is no one correct method for making notes. However, counselors should point out the following suggestions to students:

a) Notes can be made easier by using well-known abbreviations.

b) Listen carefully and recording main points, examples, new words, etc.

c) Start each topic on a new sheet or notepaper.

Despite the laudable educational policy, the aims and objectives of education are yet to be fully achieved in Nigeria because of some behavioral problems. (Mbanefo, 2000). These behavioral problems are generally negative and unhealthy thus they inhibit teaching and learning. Mbanefo (2000), observed the following behavioral problems that are existing in both secondary and post-secondary institutions: examination malpractice, insubordination, moral decadence, stealing, rioting, drug abuse, cultism, rape and alcoholism. Prominent among these behavioral problems is examination malpractice otherwise referred to as cheating in an examination because it reduces good study habit and makes the students grow lazy in academic work.

To improve the situation, scholars and researchers have made numerous suggestions and recommendations, while some recommended proper funding, effective supervision of the 
system (Jackson, Johnson and Persico, 2015). Others suggested guidance and counseling technique (Omoegun, 2012: Olusakin, 2013). The suggestions given by these scholars therefore offer a big challenge to counselors and the professionals in general on how best to tackle the problems and difficulties associated with poor reading skills and note taking and by extension mass failure and examination malpractices. It is against this background that this study attempts to investigate the effectiveness of some counselling techniques in improving reading skills and note taking among Nigerian students, on the premise that probably this may serve as solution to remediating mass failure and examination malpractices.

Study habit according to Mendezabal (2013), is the degree to which the student engages in regular acts of studying that are characterized by appropriate studying routines (e.g. reviews of material, frequency of studying sessions, and so on.) occurring in an environment that is conducive to studying. The concept of study habit comprises of study attitude, study method and study skill (Roya \& Murthy, 2016). Study, when directed to schoolwork is defined as a chain of systematic behavior pattern acquired and specifically diverted towards the acquisition of knowledge with a view to passing examinations and getting better grades. Poor study habit can occur when a student finds it difficult to retain the knowledge acquired and finds it difficult to pass examination without been involved in examination malpractice. Students who are having poor study habit may lack confidence in their self-worth they don't do assignment as at when due. Poor study habit makes students to lack self-control in their areas of study which show in their inability to retain and recollect what they have studied during examination. The inability of students to use the library effectively may be a sign of poor reading skills and note taking. Majority of students with poor study habit find it difficult to copy notes during lectures or from text books. They have nothing to depend on when examination comes. Poor reading habit is one of the factors responsible for poor study habit among secondary school student, other activities like browsing on the net has replaced their reading habits.

There have been a lot of literatures on how to make students form good study habits. According to Fadun (2005), students should develop study habit skills; such study skills would help the students to develop confidence in his self-worth to attack any assignment no matter how tough. They help students to control the study area, develop the necessary courage that requires active recitation, and review even before the crucial examinations (Bulama, 2001).

Ihuoma (2009), viewed study skills as instrumental for effective learning and subsequent higher academic performance. The focal points of these skills according to them, should center on planning a programme of study, how to use a library, taking notes at lectures and from books, how to learn and remember, and how to prepare for and take examination.

According to Omoegun (2012) the general understanding in Nigeria these days is that most people no longer read at all. They do not consider reading as an important aspect of life. These days, students prefer to watch movies and home videos. The introduction of internet technology has not helped the matter. Instead of reading, most student spend hours browsing at the cyber cafe, some of them work overnight at the cafe. This singular act is reducing the reading culture and study habit. The situation needs drastic action to arrest the decline in reading culture which hinders adequate reading and studying habit or else, the aims and objectives of education may not be achieved.

Poor study habit and note-taking is one of the factors responsible for poor performance in public examinations. Unless this problem is resolved using appropriate counselling interventions, it would be difficult for students to perform well in their various examinations. 
Against this background, the researcher of this study selected behavioral strategies to change or improve the reading and note taking habits of students.

Adeyemo (2003), further explain that the situation is so bad that many Nigerians and interested stakeholders including employers of labour have lost confidence in the value of examination and their results. It may appear that the society is not doing enough to deter cheating in the educational institutions. The cost involved in curbing the practice and to restore stakeholders' confidence in these examinations is huge. Examination malpractice be acts or actions that are wrong which are carried out by individuals or groups with the deliberate intention to cheat or unfairly gain advantage in an examination. (Arogunyo, 2007)

The employment of psychological intervention has been attested to as being a veritable tool to use, unfortunately, this has been inactive in Nigerian secondary schools. Among many treatment strategies which can be used to assist learners who perform poorly in their studies, especially in English language, the researcher has identified two strategies, namely cognitive restructuring (CR) and problem-solving (PS) to be used to ameliorate the problem. The skills arising from these two treatments have been noted to be effective in improving academic performance. To the knowledge of the researcher, students in our secondary schools in Ondo State are not equipped with the learning skills emanating from these two strategies.

It is clear that lack of cognitive restructuring and a problem-solving skill required for productive learning and studying among secondary school student are a serious problem. The manifestation of poor approach to studying interferes with the acquisition of acquiring information/knowledge, ability to be assertive, development of high self-esteem, high selfconcept, high level of motivation and psychological adjustment (Roya and Murphy, 2016). To ameliorate the undesirable effects of this behaviour, this study sets out to employ cognitive restructuring and problem-solving techniques in improving the poor study habits.

Cognitive restructuring and problem-solving strategies are therapies which emphasize behavioral change. Both are therapeutic methods developed to modify learning behaviors. Cognitive restructuring is an approach, which was developed by Ellis (1996). As a psychoanalyst, Ellis argued that, the primary causes of human distress are not unconscious impulses. On the contrary, Ellis maintained that certain core irrational ideas are at the root of most of human misery. The underlying assumption of this theory is that, a man feels and acts according to his thought. That is, as you think, so shall you feel and act. This fact is clearly illustrated in Ellis' A-B-C's paradigm. A basic premise of Cognitive Restructuring therapy is that, feel and behave and the impact they have on others. A student for instance who believes and tells himself that it is impossible for a student to pass an examination without cheating in the examination hall would certainly be involved in examination malpractice. However, if such a student can be effectively taught how to engage himself in a positive self-verbalization towards the conduct of examination, he would possibly develop a negative attitude against examination malpractice. Such a student would believe and tell himself that he could pass his examinations through hard work, commitment, good study Habit, and confidence in "selfworth" rather than engaging himself in examination malpractice. Cognitive restructuring technique has been clearly shown to be effective in behavior modification as an active and direct teaching to dispute and restructure irrational thoughts and beliefs. Its efficacy in improving self-esteem and positive change in factors within learners is evident from the review of literature . 
Cognitive restructuring has its roots in the elimination of distorted or invalid inferences, disputing irrational thoughts or beliefs. Examples of researchers that have used cognitive restructuring and problem-solving was in Nwaneri (2001) the two strategies were used to improve organizational climate behaviour for creativity and innovation among middle managers. Arogunyo (2007) established the effect of assertiveness training and cognitive restructuring on student's academic self-concept and attitude towards examination malpractice. Tayo-Olajubutu (2011) investigated the effect of cognitive restructuring and selfmanagement strategies on the discrimination against the girl-child in Ondo State. The finding of the study confirmed that both treatment strategies were effective in moderating and stabilizing family discriminatory behaviour.

Another technique of learning which this study considered is problem-solving. The propagators of this theory D'Zurilla and Goldfried (1971) defined the technique as "a behavioral process, whether overt or cognitive in nature, which (a) makes available a variety of potentially effective response alternatives for dealing with the problematic situation and (b) increases the probability of selecting the most effective response as a cognitive activity aimed at changing a problem from a given state to the goal state. It refers to directed cognitive processing. Problem-solving is directed because the problem solver is motivated by a desire to achieve a goal; it is cognitive because it occurs within the problem solver and can only be inferred from the problem solver's actions. Problem-solving is a process because information is manipulated or operated upon within the problem solver. The general goals in all problemsolving training, however, is not to provide individuals with specific solutions to specific problematic situations, but rather to provide a general coping strategy, so that they may be in a better position to deal more effectively with a wide variety of situational problems. D'Zurilla and Goldfried (1971) state that the inability to arrive at an adequate solution in a problematic situation, may not only serve to upset us, but may have some negative consequences that will only create further problems in future.

D'Zurilla and Goldfried (1971) developed a five-step model which secondary school students can use effectively to solve academic problems. These are: problem orientation (b) problem definition and formulation, (c) generation of alternative solutions, (d) decision-making, (e) solution implementation and verification. In the words of Aremu (2011), the goals of problemsolving are to stimulate behavior, which is likely to produce a positive consequence, that is positive reinforcement. He observes further that training in problem-solving may be viewed as one of several possible behavior modification techniques for facilitating effective change in behavior.

Rohtak and Rohtak, (2016) defines problem solving as the framework or pattern within which creative thinking and reasoning take place. It is also a process of eliminating the discrepancy between the actual and desired situation (Khan, Hafeez, Saeed and Khan, 2012). Areas where problem solving have been used are: Orimogunje (2003) who examined the relative effectiveness of problem- solving and lecture method on secondary students' achievement in chemistry but the problem-solving strategy assisted students to think logically and finding solutions to problems. Olorunfemi (2008) investigated the effectiveness of self-management and problem-solving strategies in the improvement of students with poor academic performance, the result showed that the treatment strategies were effective in improving academic performance. Oliha (2014) investigated differential effectiveness of contingency management and cognitive restructuring in the reduction of truancy among secondary school adolescents. The results obtained indicated significant differences in truant behaviour of students exposed to treatment strategies than those in control group. Also, significant 
difference existed in truancy treatment between students exposed to contingency management strategy and those exposed to cognitive restructuring.

\section{STATEMENT OF THE PROBLEM}

The recurring declining performance of students at secondary school level of education due to poor reading skills and note taking behavior is the concern for this study. Previous studies and observations among many other reasons are responsible for failure of secondary school students, also, inability to properly plan and organize time for study, poor note taking, ineffective method of preparing and taking examinations are the causes of academic poor performance. Perhaps if some counselling strategies for reading and examination preparation techniques are introduced there may be improvement. The purpose of the study is to investigate the effects of cognitive restructuring and problem solving strategies on poor reading skills of students and how to improve the note taking skills of students.

\section{RESEARCH HYPOTHESES}

1. There is no significant difference in the reading and note taking habits of students exposed to cognitive restructuring strategy and those in the control group.

2. There is no significant difference in the reading and note taking habits of students exposed to problem solving strategy and those in the control group.

\section{METHODOLOGY}

The study employed a descriptive research design of survey type to investigate the effect of the independent variable (Cognitive restructuring and Problem Solving strategies) on the dependent variable (reading and note taking).

The population of this study consisted of the entire senior secondary school students in Ondo State.

The sample for the study consisted of one hundred and twenty (120) students from three secondary schools in the state. The sample were selected using multi- stage sampling technique. The local government, schools, and subjects were selected using stratified and simple random techniques.

The instrument used for this research was Study Habits Inventory (SHI) and was adapted from Bakare (1977) and used as pretest and post-test for students' study habits. The study habits Inventory (SHI) consisted of two sections. Section A consisted of items that sought information on the personal data of the respondents (class, age, sex and school) while Section B contained 45 items measuring various dimensions of study habit.

The test experts from the Department of Guidance and Counselling agreed that the instrument had face validity. For further scrutiny for the content validity, the test experts studied the item and they all agreed that the items are adequate in measuring the various dimensions of students' study habits.

To establish the reliability of this scale, a Cronbach Alpha Internal Consistent Reliability was employed. The 45 item-test was administered on some selected subjects outside the sample group. The value of coefficient obtained from the test was 0.76 . This coefficient represented a relatively high degree of stability and suggested that the scale is a relatively stable instrument; thus, confirming the reliability of the instrument. 
The instrument for data collection was administered on the subjects in their various schools with the help of a research assistant, and some of the school counselors. The subjects in the experimental group were exposed to the two treatment packages while those in the control group were not.

The data collected were analyzed using analyses of co-variance (ANCOVA).

\section{Hypothesis 1}

\section{RESULT AND DISCUSSION}

There is no significant difference in the reading and note taking of students exposed to cognitive restructuring strategy and those in the control group.

Mean scores relating to the reading and note taking of students exposed to cognitive restructuring and the control groups were computed and compared for statistical significance using Analysis of Covariance (ANCOVA) at 0.05 level of significance. The result is presented in Table 1.

Table 1: ANCOVA showing reading and note taking of students in the cognitive restructuring and control groups

\begin{tabular}{|l|l|l|l|l|l|l|}
\hline Source & SS & df & MS & $F_{\text {cal }}$ & P & $F_{\text {table }}$ \\
\hline Corrected Model & 373.488 & 2 & 186.744 & 22.433 & 0.000 & 3.11 \\
\hline Covariate (Pretest) & 57.476 & 1 & 57.476 & 6.904 & 0.010 & 3.96 \\
\hline Group & 293.492 & 1 & 293.492 & $35.256^{*}$ & 0.000 & 3.96 \\
\hline Error & 640.999 & 77 & 8.325 & & & \\
\hline Corrected Total & 1014.487 & 79 & & & & \\
\hline Total & 45713.000 & 80 & & & & \\
\hline
\end{tabular}

${ }^{*} \mathbf{P}<0.05$

Table 1 clearly revealed that there was statistical significant difference in the reading and note taking of students exposed to cognitive restructuring strategy and those in the control group $(\mathrm{F}=35.256, \mathrm{P}<0.05)$. The null hypothesis was rejected. Therefore, there was significant difference in the reading and note taking of students exposed to cognitive restructuring strategy and those in the control group.

Multiple Classification Analysis (MCA) was used to determine the effectiveness of treatment (strategies) on reading and note taking ability of the students. The result is presented in Table 2.

Table 2: Multiple Classification Analysis (MCA) showing the effect of counseling strategies on reading and note-taking of students

\begin{tabular}{|l|l|l|l|l|l|}
\hline \multicolumn{7}{|c|}{ Grand Mean =23.64 } & Beta \\
\hline Variable + Category & $\mathbf{N}$ & $\begin{array}{l}\text { Unadjusted } \\
\text { Devn' }\end{array}$ & Eta $^{2}$ & Adjusted For Independent + Covariate & .28 \\
\hline Cognitive Restructuring & 40 & 1.98 & .37 & 1.90 & .281 \\
\cline { 5 - 7 } & 40 & -1.99 & & -1.91 & .079 \\
\hline $\begin{array}{l}\text { Control } \\
\text { Multiple R }\end{array}$ & & & & .28 \\
\hline
\end{tabular}


Table 2. showed that, with a grand mean of 23.64, students exposed to cognitive restructuring had higher adjusted mean score of $25.54(23.64+1.90)$ on reading and note-taking than their counterparts in the control group with an adjusted mean score of $21.73(23.64+(-1.91)$. This implies that cognitive restructuring strategy constitutes a veritable counseling therapy for enhancing students' ability in reading and note-taking. The treatment explained about 37\% $\left(\mathrm{Eta}^{2}=0.37\right)$ of the observed variance in reading and note-taking ability of students.

\section{Hypothesis 2}

There is no significant difference in the reading and note taking of students exposed to problem solving strategy and those in the control group

To test the hypothesis, mean scores of students in the problem-solving and control groups on reading and note-taking were computed and compared for statistical significance using Analysis of Covariance (ANCOVA) at 0.05 level. The result is presented in Table 3.

Table 3: ANCOVA showing reading and note taking by students in the problem-solving and control groups

\begin{tabular}{|l|l|l|l|l|l|l|}
\hline Source & SS & df & MS & $F_{\text {cal }}$ & P & $F_{\text {table }}$ \\
\hline Corrected Model & 181.296 & 2 & 90.648 & 10.541 & 0.000 & 3.11 \\
\hline Covariate (Pretest) & 4.283 & 1 & 4.283 & 0.498 & 0.482 & 3.96 \\
\hline Group & 168.785 & 1 & 168.785 & $19.626^{*}$ & 0.000 & 3.96 \\
\hline Error & 662.192 & 77 & 8.600 & & & \\
\hline Corrected Total & 843.488 & 79 & & & & \\
\hline Total & 43671.000 & 80 & & & & \\
\hline
\end{tabular}

${ }^{*} \mathbf{P}<0.05$

Table 3. revealed that there was significant difference in the reading and note taking of students exposed to problem solving strategy and those in the control group $(\mathrm{F}=19.626$, $\mathrm{P}<0.05)$. The null hypothesis is rejected. This implies that there was significant difference in the reading and note taking of students exposed to problem solving strategy and those in the control group.

Multiple Classification Analysis (MCA) was used to determine the effect of treatment on reading and note-taking ability of the students. The result is presented in Table 4.

Table 4: Multiple Classification Analysis (MCA) showing the effect of counseling strategies on reading and note-taking of students

\begin{tabular}{|c|c|c|c|c|c|}
\hline \multicolumn{6}{|c|}{ Grand Mean $=23.14$} \\
\hline Variable +Category & $\mathbf{N}$ & $\begin{array}{l}\text { Unadjusted } \\
\text { Devn' }\end{array}$ & Eta $^{2}$ & Adjusted For Independent + Covariate & Beta \\
\hline Problem-Solving & 40 & 1.54 & \multirow{2}{*}{.22} & 1.45 & \multirow{2}{*}{.12} \\
\hline Control & 40 & -1.49 & & -1.45 & \\
\hline Multiple R & & & & .122 & \\
\hline
\end{tabular}


Table 4. shows that students exposed to problem-solving strategy had higher adjusted mean score of $24.59(23.14+1.45)$ than those in the control group; $21.69(23.14+(-1.45)$. Therefore, the use of problem-solving counseling therapy would improve students' reading and notetaking ability. About $22 \%$ of the observed variance in reading and note-taking of clients is attributed the treatment (Counseling strategy).

\section{DISCUSSION}

Hypothesis one states that there was no significance difference in the reading and note taking of subjects exposed to cognitive restructuring strategy and those in the control groups. The result reveals that the treatment had significant effects on the subjects. There is an indication that the subjects exposed to cognitive restructuring strategies improve better than those in the control group in reading and note taking of students exposed to cognitive restructuring techniques and those in the control group.

The result confirmed the study of Hoffman et al (2012) that examine cognitive behaviour therapy with substance use disorder, schizophrenia and other psychotic disorder. This study also supports Tayo Olajubutu (2011) who investigated the effects of cognitive restructuring and self-management strategies on discriminatory behavior against the girl-child among families in Ondo State. The finding of the study confirmed that both treatment strategies were effective in moderating and stabilizing family discriminating behaviour.

Wolgast et al (2013) confirmed the efficacy of cognitive restructuring in regulating general dimensions of emotion which consisted of several sub-construct or conceptual nuances which somewhat different psychological functions and properties.

Hypothesis two states that there is no significant difference in the reading and note taking of subjects exposed to problem solving strategies and those in the control group. The result reveals that the treatment had significant effects on the subjects. There is an indication that the subjects exposed to problem-solving techniques improved better than those in the control group. In reading and note taking. Thus, the hypothesis is not accepted.

This means that there is a significant difference in the reading and note taking of subject exposed to problem-solving techniques and those in the control group. The results corroborate the problem-solving skills pioneer research studies of D'Zurilla and Goldfriend (1971) who confirmed in their experimental studies that problem-solving approaches are effective in improving study habits. The finding supports Olorunfemi (2008) who investigated the effective of self-management and problem-solving techniques in the improvement of subject with poor academic performance.

\section{CONCLUSION}

Generally, the conclusion drawn from the findings of the study indicated that both cognitive restructuring and problem-solving techniques are effective strategies which can be utilized by school administrators and counselors not only to enhance students reading and note taking but also to improve academic performance and the qualities of students.

\section{RECOMMENDATIONS}

The research finding has shown that there is need for guidance counselors to be provided in all schools so that they can use their different strategies in solving students' problems. 
There is need for the Government to embark on enlightenment campaign on how to improve the reading culture and note taking of students especially these days when it appears there is a decline in the reading culture of students.

Practicing guidance counselors are enjoined to use appropriate counseling techniques for example cognitive restructuring and problem-solving techniques in solving the problems of their clients using these findings as a reference point.

Students should be actively taught with guidance on how to develop effective reading and note taking with a view to improving their academic performance.

In solving the numerous problems facing the students, government should provide more relevant text books that will encourage reading and note taking.

\section{References}

Adeyemo, T. A. (2003). Effects of Self-Efficacy on Academic Self-Efficacy, Emotional Intelligence, Academic Motivation and Academic Interest of Educational Distressed Students. (Unpublished M. Ed thesis), University of Ibadan, Ibadan.

Anwar, E. (2014). A correlational study of academic achievement and study habits: Issues and concerns. Excellence International Journal of Education and Research, 1(2), 46-51.

Aremu, O. D. (2011). Effects of two group counselling approaches on self- concept, locus of control and attitude of selected adolescents towards science. (Unpublished PhD thesis), University of Ilorin.

Arogunyo, A. E. (2007). Effects of assertiveness training and cognitive restructuring on students' academic selfconcept and attitude towards examination malpractice. (Unpublished Ph.D thesis) Adekunle Ajasin University, Akungba Akoko.

Azeez, G (2009). Study problem behaviours of students. (Unpublished Monograph). Department of Guidance and Counselling, University of Ibadan.

Bakare C. M. G. (1977). Study habit inventory. University of Ibadan press.

Bulama, K. (2001). Developing effective study habit through counselling among Nigeria students: A Remedy for Mass Failure and Examinations Malpractices. Amodu Bello University. Journal of Counselling and Human Development, 2, 120-131.

D'Zurilla, T. J \& Goldfried (1971). Problem Solving and Behaviour Modification Journal of Abnormal Psychology, $78,107-136$.

Ellis, A. (1996). Reason and Emotion in Psychotherapy. New York: Lyle Stuart.

Fadun, P. O. (2005). An Evaluative Study of the Reinforcement, Repetition, Self-monitoring on Academic Achievement motivation. (Unpublished Ph.D thesis), University of Ibadan.

Haghverdi, H. R; Biria, R; and Karimi, L. (2010). Note-taking Strategies and Academic Achievement. Journal of Language and Linguistic Studies,

(6) $1,75-109$.

Hofmann, S. G.; Asnaani, M. A.; Imke J. J.; Vonk, M. A; Alice T.; Sawyer, M.A., \& Fang, M.A. (2012). The Efficacy of Cognitive Behavioral Therapy: A Review of Meta-analyses. Cognitive Therapy Resource, 36(5), 427-440.

Hussain, O. (2006). A study of under achievement among undergraduate in selected Nigeria Universities. Journal of Teacher Education, 1(1), 165-179.

Ihuoma, C.P (2009). Social Skills Training and Self Statement Techniques in the Treatment of Socially Anxious Adolescents in Lagos Metropolis, Nigeria. Unpublished Ph.D. Thesis University of Ibadan

Jackson, C. K.; Johnson, R. C.; Persico, C. (2015). The Effects of School Spending on Educational and Economic Outcomes: Evidence from School Finance Reforms. Quarterly Journal of Economics, 131 (1), 157-218.

Khan, S.; Hafeez, A. D. I.; Saeed, M. (2012). The Impact of Problem Solving Skill of Heads' on Students' Academic Achievement. Interdisciplinary Journal of Contemporary Research in Business, 4(1), 316-330. 
Lee, P; Wang,C; Hamman, D; Hsiao, C. and Huang, C. (2013). Notetaking instruction enhances students' science learning. Child Development Research, http://dx.doi.org/10.1155/2013/831591.

Mbanefo, I. M. A (2000). Problem behaviour of students in schools. A paper presented at the 24th annual conference of the counselling Association of Nigeria, Abuja. (August $14^{\text {th }}-18^{\text {th }}$ ).

Mendezabal, M. J. N. (2013). Study Habits and Attitudes: The Road to Academic Success. Open Science Repository Education, Online(open-access), e70081928. doi:10.7392/Education.70081928.

Nwaneri, A. C (2001). Problem - solving and cognitive restructuring techniques in the improvement of organizational climate behaviour for creativity and innovation among middle managers in Ibadan. Unpublished PhD Thesis, University of Ibadan.

Oliha, J. A. (2014). Differential effectiveness of contingency management and cognitive restructuring in the reduction of truancy among secondary school adolescent. Journal of Studies in Social Sciences, 6(1), 15-22.

Olorunfemi, O. F. (2008). Effects of self-management and problem-solving techniques on academic performance of secondary school students in Ondo State. Unpublished PhD Thesis, Adekunle Ajasin University, Akungba Akoko.

Omoegun, O.M (2010). Paper presented on Student Study Habit at University of Lagos

Orimogunje, T. (2003). The relative effectiveness of problem-solving and lecture methods on secondary school students' achievement in Chemistry. (Unpublished Ph.D. thesis), Ekiti State University, Ado-Ekiti.

Pitan 0. O. (2011). Poor study habits as educational problem among university undergraduate and effective management strategies. International Journal of Humanities and Social Invention, 2)72-76.

Rohtak, M; Rohtak, P.; Rohtak, S. (2015). Effect of problem solving ability on academic achievement of high school students: a comparative study. Bhartiyam International Journal of Education \& Research,4(2),

Roya, S. \& Murthy, C. G. V. (2016). Study habits and academic achievement among secondary and senior secondary school students of Mysore City. The International Journal of Indian Psychology, (3)3, 161-170.

Tayo-Olajububtu, O. (2011). The effect of cognitive restructuring and self-management stratregies on discriminatory behaviour against the girl-child. An unpublished Ph.D. thesis, Adekunle Ajasin University, Akungba-Akoko.

Wolgast, M; Lundh, L; and Gardar, V. (2011). Cognitive restructuring and acceptance: An empirically grounded conceptual analysis. Cognitive Therapy and Research, 37(2), 340-350. 